\title{
From cut-points to key players in co-authorship networks: a case study in ventilator-associated pneumonia research
}

\author{
Gregorio González-Alcaide ${ }^{1}\left(\mathbb{D} \cdot\right.$ Héctor Pinargote $^{2} \cdot{\text { José } M . \text { Ramos }^{3}}^{2}$
}

Received: 11 April 2019 / Published online: 28 February 2020

(c) Akadémiai Kiadó, Budapest, Hungary 2020

\begin{abstract}
In co-authorship networks, some nodes play the key role of cut-point, facilitating the integration of other authors and favoring connectivity among different research communities. The present study uses bibliometric and network embeddedness indicators to analyze the scientific activity on ventilator-associated pneumonia and the roles of 17 research communities and 30 cut-points therein. In addition to fostering network connectivity and cohesion, cut-points are characterized by other differential features compared to other authors, including a much higher level of productivity and greater participation in leadership positions, higher betweenness values, lower clustering coefficients and higher levels of constraint. The cut-points identified have different characteristics in terms of the connectivity they facilitate between research communities: some cut-points have established weak intercommunity ties in the form of bridges with a single author from a different community; in other cases, they serve as gatekeepers due to their connection with different authors of a community that they link with their own; cut-points may also act as structural folds, that is, actors with an overlapping role between two cohesive communities. The cut-points present very diverse connectivity degrees, with some cut-points whose elimination would provoke severe network fragmentation and others who are responsible for linking far fewer external authors to their network. The cut-points that present both the main mechanisms for obtaining social capital — that is, filling structural holes and participating in cohesive network structures - can be considered key actors/players because their participation is crucial for ensuring both integration into the main research focus of some communities with high research performance and the overall cohesion of a co-authorship network.
\end{abstract}

Keywords Pneumonia $\cdot$ Research performance $\cdot$ Connectivity roles $\cdot$ Bridges · Gatekeepers · Brokers

Gregorio González-Alcaide gregorio.gonzalez@uv.es

1 Department of History of Science and Documentation, University of Valencia, Valencia, Spain

2 Department of Internal Medicine, General University Hospital of Alicante, Alicante, Spain

3 Department of Clinical Medicine, Miguel Hernandez University of Elche de Elche, Alicante, Spain 


\section{Introduction}

Different studies have signaled the importance of identifying and promoting the investigative activities of certain authors in order to advance research in a given discipline or area of knowledge. These authors establish new lines of research; facilitate multidisciplinary, interdisciplinary, and transdisciplinary approaches to research problems; facilitate cooperative practices between researchers from different groups and institutions; work actively to integrate new researchers into their networks; and expedite the translation of research evidence into clinical practice (Gray 2008; Long et al. 2013a, b).

It is possible to identify the most productive authors of a discipline or area of knowledge through multidisciplinary bibliographic databases like the Web of Science (WoS) or Scopus, or more recently through specific tools like the Highly Cited Researchers of Clarivate Analytics, which shed light on researchers' performance based on citations and the visibility or impact of the journals publishing their work. However, in recent years social network analysis (SNA) has also emerged as an important tool in this line of inquiry, leading to the development of different indicators for identifying the most influential agents, either with respect to their centrality in their networks (Freeman 1979; Valente et al. 2008), a function of the social capital derived from their degree of embeddedness in the networks, or because they enable the connectivity and integration of other agents or nodes in those structures through their role as brokers or cut-points (Harary et al. 1965; Long et al. 2013b), that is, the pivotal points of articulation between the elements that make up a component (Harary et al. 1965; Scott 1991).

Since the pioneering contributions of Bavelas (1950) and Leavitt (1951), and the influential study by Freeman (1979), a wide body of research on network theory has focused on the concept of point centrality (local centrality). High network centrality refers to a point in the network located at the nexus between many other nodes, with an abundance of direct connections to others (Harary et al. 1965; Scott 1991). Numerous studies analyzing scientific co-authorship networks have tried to determine the existing relationships between different researchers' indicators of centrality and their scientific performance (Abbasi et al. 2011; Abbasi et al. 2012; Badar et al. 2013; Bordons et al. 2015; Uddin et al. (2012); Yan and Ding 2009).

More recently, another line of research has aimed to analyze the benefits that individuals or agents may obtain from participating in networks, basing their work on the concept of social capital, as measured by their degree of embeddedness within these structures. Social capital is used conceptually to interpret and explain an individual's success, beyond their personal attributes or capacities. It can be defined as the benefits in the form of recognition, knowledge, or resources that they can obtain from the stable network ties they have established (Bourdieu 1986; Nahapiet and Ghoshal 1998).

The two principal theories that have been proposed to explain how social capital is created and mobilized is based on two opposing approaches. The one put forward by Coleman revolves around the idea of network closure, and it holds that cohesive network structures (dense connections to others who are also connected to each other) represent the essential mechanism for generating social capital, building trust and cooperation among individuals, among other benefits (Coleman 1988). On the other hand, Burt's structural hole theory posits the existence of empty spaces in social networks and non-redundant contacts, or networks held loosely together by agents connecting segments that would otherwise remain detached. Filling these holes opens up new opportunities to access knowledge and nonredundant skills, thus generating more social capital (Burt 1992). 
With regard to these two theories on the acquisition of social capital, it is important to consider the intensity of the ties or interactions established between network members. Granovetter (1973) argued that studying weak ties (sporadic or isolated collaborations) provides different information than that gleaned from a focus on strong ties. As applied to scientific co-authorship networks, the members of a research community with (weak) ties to members of other communities would confer an added value, facilitating information flows and innovations and serving as reference nodes for their networks (Woolcock and Deepa 2000; Putnam 2001). This vision is consistent with the concept of structural holes. However, other authors maintain that the strong ties are associated with better scientific performance, and this view is more consistent with the idea of cohesive or closure networks (Liao 2011; McFadyen et al. 2009).

Nahapiet and Ghoshal (1998) contributed greatly to developing the network embeddedness dimensions of social capital theory, including with regard to the intensity of the ties established between network agents. These authors made a distinction between structural embeddedness, relational embeddedness, and cognitive embeddedness:

- Structural embeddedness refers to the pattern of connections between the analyzed agents. In scientific collaboration networks, it can be assessed using centrality indicators like betweenness or closeness, which establish the pre-eminent position of scientific agents within the overall network structure, the pattern of connections, and the possibilities and channels for accessing the rest of scientific agents therein (Borgatti 2006a; Freeman 1979; Otte and Rousseau 2002). Measuring the density of connections among individuals also provides information about the structural dimensions of the networks, which is linked to the clusters and the establishment of non-redundant ties between network members (Coleman 1988; Burt 1992).

- Relational embeddedness measures the breadth and intensity of the established ties and can be determined in scientific co-authorship networks based on its degree and especially by quantifying the intensity of the collaborations established. This dimension is reinforced in the presence of a strong identification with the group, trust within its membership, a perception of needing to participate in the group's activities, and recognition of and support for group norms (Wasko and Faraj 2005; Ahuja 2000; Reagans and McEvily 2003).

- Cognitive embeddedness involves assuming the norms and practices that characterize a given collective (e.g. a discipline or profession) and which are learned and reinforced over time and through experience and interaction among group members and professional practices. In scientific co-authorship networks, it is possible to study this dimension by identifying the length of time different agents have spent working in the field (which will affect the length of the learning and socialization period) or by determining the fields of knowledge in which they work.

There is abundant literature that supports the idea that a company's embeddedness in networks (generated from the analysis of the ties established with other firms) is a key element for interpreting the processes by which social capital is generated, and by which innovation, complementarity, access to intellectual or technological capital, and ultimately businesses or markets can thrive (Ahuja 2000; Gilsing et al. 2008; Nahapiet and Ghoshal 1998). In this area, social capital mainly relies on organizational culture and can be transmitted through the firm's alliances or collaboration networks (in business, it is the institution that transmits working methods, know-how, and values when workers operate within them) (Ravasi and Schultz 2006). However, scientific knowledge and advances are more 
closely linked to individual researchers or scientific agents, and particularly to the research groups they participate in. These are increasingly heterogeneous and informal, and their boundaries are not determined by the institutions with which researchers are affiliated. Indeed, research groups are becoming more interdisciplinary and geographically dispersed (Adams et al. 2005; Jones et al. 2008). For that reason, it is of great interest to analyze the social capital derived from the structures formed by research groups and the role that "brokers" play in connecting these groups through scientific collaboration networks. Currently, the scientific evidence on this topic is scarce. In that sense, Bozeman et al.'s (2013) literature review on research collaboration, which analyzed individual-level collaborations among academic researchers, called for analyses on multiple levels, along with the study of between-level interactions and greater measurement of impact instead of output.

The present study is contextualized within the body of research on social capital, as applied to scientific co-authorship networks. Both of these aspects are examined, as we combine analyses at the micro (researchers) and meso (research groups) levels to analyze the role played by researchers in ventilator-associated pneumonia (VAP) who serve as "brokers" or connectors between different groups or research communities. We also assess the extent to which the degree of embeddedness affects both researchers' outputs and their impact. We chose the area of VAP due to its modest volume of publications (1964 documents published from 2006 to 2017 in the WoS), enabling its detailed analysis from subject-area experts on our author team. Moreover, this field presents general characteristics that are similar to those observed in many other areas of biomedical research. For example, Ramos-Rincón et al. (2019) have analyzed global scientific production on pneumonia from 2001 to 2015, which encompasses the area of VAP examined here. That study highlighted the steady growth in scientific production in the field; this was concentrated in the USA and Europe, although with marked incursions from China, which emerged as the second-most productive country in the most recent study period (2011-2015). International collaboration showed slow but steady growth, with $22 \%$ of the documents in the most recent period signed by authors from more than one country. European countries presented a higher degree of international collaboration than the USA, while North America had a higher degree of citation than Europe. The values observed for the rest of the countries studied were much lower.

Numerous studies have analyzed the structural dimension of scientific co-authorship networks, primarily through three of the most common centrality measures (degree, closeness, and betweenness). These authors have aimed to assess the prominence of different agents in scientific networks or analyze the relationship between these measures and the output or impact of publications (Kumar 2015). However, few studies have tried to characterize social embeddedness in scientific collaboration according to Nahapiet and Ghoshal's (1998) dimensions and assess their impact on performance. Some contributions that stand out include González-Brambila et al.'s (2013) study, which analyzed the effect of embeddedness on research output and scientists' impact, based on the documents published with participation from at least one Mexican author from 1981 to 2002 in the Science Citation Index and Social Sciences Citation Index. For their part, Li et al. (2013) studied the papers published in 1999-2003 in five high-impact Information Systems journals; these authors selected 137 investigators and analyzed the extent to which the social capital embedded in their co-authorship networks influenced the impact of their publications. We review the implications of these studies, along with other contributions addressing more specific indicators or aspects, in the Discussion.

Once we identified the existing research clusters or communities that characterize the small-world co-authorship networks in any area of knowledge (Newman 2001, 2004), 
including VAP, we used the concept of cut-points from graph theory to identify the most relevant scientific agents, whose role as brokers is essential for ensuring connectivity between different communities and the overall cohesion of the network. Briefly, cut-points are nodes that ensure the connectivity and global cohesiveness of the networks. The elimination of these points would cut some areas of the network off from others, increasing the number of components and reducing their size. Doreian and Fujimoto (2004), Borgatti (2006b), and Valente and Fujimoto (2010) have all used the concept of cut-point and their inherent property of connectivity to identify the relevant nodes (linking-pin, key players, bridges) that make up social networks. However, we have not identified any paper that specifically analyzes the role of cut-points in scientific co-authorship networks in more depth than a few isolated allusions to studies analyzing the existing relationship between centrality measures and scientific performance (Abbasi et al. 2011; Kumar 2015). The present study aims to fill that gap, describing the role of these researchers (cut-points) as they are related to the embeddedness dimensions and their differential characteristics relative to other authors participating in scientific co-authorship networks.

\section{Objectives}

The objective of the present study is to identify the existing VAP research communities and analyze the embeddedness role played by cut-points in promoting research in the area. Considering the conceptualization of cut-points described, we aim to determine whether these obtain their social capital (output and impact) solely from their role as brokers and their intermediate position between different structural holes. The following specific research questions will be explored.

- How are relationships between different research communities produced and what role do cut-points play in enabling that connectivity?

- Do cut-points present differential features related to their research performance compared to the rest of the authors?

- Do the ego-networks of the cut-points present similar features, or is it possible to distinguish different types of structures?

\section{Methods}

The performance of the study proceeded as follows.

\section{Determination of the population of included documents and standardization of bibliographic data}

We identified all documents assigned with the Medical Subject Headings (MeSH) descriptor "Pneumonia, Ventilator-Associated" which were included in the WoS Core Collection databases. Although these databases do not include all documents indexed in MEDLINE/ PubMed, they do index the contents of the journals with the highest international impact and include data on all institutional affiliations along with citation indicators, making this the most appropriate source to address the study objectives. The search was limited to the 2006-2017 period and to articles and reviews, in order to identify and analyze the research 
communities and authors who are actively generating knowledge in the area through the main document types that report original research results.

Once the body of included documents was defined, we downloaded the bibliographic data and standardized the author signatures to unify variants of authors' name (arising from the use of, for example, different initials for the given name, hyphens to unify different elements, or spelling mistakes in the final publication). Because we analyzed the research community in a very specific area of knowledge, correct identification and treatment of the authors' names was relatively straightforward. Upon encountering variants of a signature that could potentially correspond to the same author, we consulted the institutional affiliation and subject category of the papers associated with each variant. The variants were joined and standardized in case of overlaps, and in case of discordance, we consulted additional sources, such as the CVs on institutional websites, to determine if the differences responded to factors like research mobility by a single author.

\section{Generation of co-authorship network and identification of research communities and cut-points participating in them}

\section{Construction of co-authorship network}

Based on the identification and quantification of the co-authorship links, we generated a co-authorship network, that is, a visual representation (graph) showing a group of nodes or vertices, representing different authors of scientific publications, along with links between the nodes, representing co-authorships (joint signatures from one or more scientific publications). In order to produce an overview of the generated network, general and structural SNA indicators were obtained (Table 1).

\section{Identification of the main research sub-network}

After the overall characterization of the co-authorship network, the analysis focused on the stable and consolidated research communities representing the main research sub-network of the area analyzed. An edge-weight threshold was used for an in-depth analysis of the network, eliminating the sporadic co-authorship ties ( 1 or 2 co-authorships) to identify the research communities with stronger bonds. The more papers co-signed by two authors, the higher the edge-weight threshold (or collaboration intensity); elevated values represent a stable, consolidated cooperative association, making it relevant for the analysis undertaken. The concept of main research sub-network we use refers to the authors comprising the largest component of the generated sub-graph, once isolated collaborations are eliminated. Graphically, collaboration intensity is expressed by the thickness of lines linking the nodes.

\section{Identification of research communities and cut-points}

Next, we identified the main research clusters or communities existing in the main research sub-network, along with the cut-points participating in them. A research cluster or a research community can be defined as a sub-graph, or groups of authors that maintain a higher degree of interconnectedness (and thus level of cohesion and differentiation) than other sub-graphs in the network, with which they may also be related. After testing several algorithms, we opted to apply Persson's Party Clustering algorithm, in the Bibexcel program, to identify existing research clusters or communities (Persson et al. 2009). The cut-points are nodes through 
Table 1 Social network analysis (SNA) indicators used in this study for characterizing global co-authorship network

\begin{tabular}{|c|c|}
\hline Indicator & Definition \\
\hline Number of nodes & Total number of nodes (authors) in the network \\
\hline Number of lines & $\begin{array}{l}\text { Number of different links (co-authorships) between } \\
\text { network members }\end{array}$ \\
\hline Average degree & $\begin{array}{l}\text { Mean collaborators of authors in the network, calcu- } \\
\text { lated by adding all the collaboration links of each } \\
\text { network author and dividing that value by the total } \\
\text { number of authors }\end{array}$ \\
\hline Network degree centralization & $\begin{array}{l}\text { Sum of the squares of the proportion of the total } \\
\text { centrality held by each node }\end{array}$ \\
\hline Density & $\begin{array}{l}\text { Proportion of the number of links in the network } \\
\text { relative to the maximum number of links that are } \\
\text { theoretically possible }\end{array}$ \\
\hline Average distance & $\begin{array}{l}\text { Mean geodesic distance between reachable author } \\
\text { pairs }\end{array}$ \\
\hline Largest distance (diameter) & Length of longest geodesic distance \\
\hline Watts-Strogatz clustering coefficient (range: 0 to 1 ) & $\begin{array}{l}\text { Measure of the mean densities of the neighborhoods } \\
\text { of all nodes in the network, i.e. the extent of cluster- } \\
\text { ing among nodes }\end{array}$ \\
\hline Modularity (range: -1 to 1 ) & $\begin{array}{l}\text { Strength of network division into "modules" (clusters } \\
\text { or communities) based on the fraction of nodes } \\
\text { that fall under each module compared with random } \\
\text { distribution of links between all nodes regardless of } \\
\text { modules }\end{array}$ \\
\hline Number of components & $\begin{array}{l}\text { Number of sub-graphs interconnected directly or } \\
\text { through intermediaries, but disconnected between } \\
\text { each other }\end{array}$ \\
\hline Size of the largest (or giant) component (\%) & $\begin{array}{l}\text { Number of interconnected nodes (authors) in the } \\
\text { largest component and \% of participating authors } \\
\text { relative to the total }\end{array}$ \\
\hline
\end{tabular}

which every other path or geodesic crosses, enabling links between other nodes. Their elimination would lead to a fragmentation of the network, making them essential intermediaries to ensure connectivity and communication throughout the network.

To identify the cut-points, nodes were selected if their elimination would result in at least five authors breaking off from the main research sub-network. This threshold recognizes that although some nodes may adhere to a strict definition of cut-point, they only sporadically link other authors together. Likewise, in some cases an author dyad served together as cut-points, so even though they did not perfectly fulfil our criteria for defining cut-points, we made the decision to consider them as such. These dyads represent a peculiarity of scientific co-authorship networks, as they work as tandem researchers on the same documents and have generated a joint role as cut-points.

\section{Bibliometric and thematic characterization of the activity of research communities and scientific agents (cut-points)}

To analyze the research activity of the research communities identified and the cut-points participating in them, we used the bibliometric and network indicators listed in Table 2, which 
we grouped according to the dimensions of embeddedness proposed by Nahapiet and Ghoshal (1998); this table also describes their calculation and interpretation.

We also generated a network in which the authors of the research communities identified were treated as aggregates in order to specifically analyze the ties between them. They were classified as follows.

- 1:1. The ties between two research communities have been established via a single author from each community.

- $1: \mathrm{N} / \mathrm{N}: 1$. A single author from one community has established two or more links with different researchers in another community.

- N:N. There are multiple collaborative ties between researchers in two interrelated communities.

To generate network representations and calculate all described indicators, we used Pajek software.

Other aspects that were analyzed include the extent to which factors like institutional affiliations (a proxy for authors' countries) and the topics addressed are associated with membership in different research communities; and differences between cut-points and other authors in relation to bibliometric and network indicators.

Finally, we correlated bibliometric indicators of scientific performance (scientific production and $h$-index) and the social network indicators using Microsoft Excel's correlation statistical function, in order to check whether there was a significant association between them and to assess potential differences between cut-points and other authors with regard to those associations.

\section{Results}

\section{Overall VAP co-authorship network}

A total of 1964 documents published from 2006 to 2017 were identified on VAP: 1696 articles and 268 reviews, with contributions from 8529 authors, of whom $0.74 \%(N=63)$ published more than nine documents, and $80.54 \%(N=6869)$ only one.

The analysis of the thematic classification of the journals showed that Critical Care Medicine (33.76\% of the documents) and Infectious Diseases $(27.49 \%)$ were by far the most common disciplines contributing to research in the area. Seven other specialties contributed with at least 5\%: Respiratory System (12.68\%), Microbiology (10.69\%), Public, Environmental \& Occupational Health (10.23\%), Surgery (8.86\%), Pharmacology \& Pharmacy (7.43\%), Nursing (6.31\%), and Medicine, General \& Internal (5.7\%).

We processed 50,164 co-author ties, $4863(9.69 \%)$ of which were repeated at least twice, generating a co-authorship network with 590 components. Over half (54.33\%) of the nodes (authors) were members of the largest component. Table 3 shows the general and structural indicators for the network. 
Table 2 Bibliometric and network indicators for characterizing the research communities identified and the cut-points within them

Definition Scope of indicator(s)

Research communities

Bibliometric indicators on research performance and collaboration

Scientific production: $\mathrm{N}$ documents and mean publications per author

Collaboration: co-author index, calculated by dividing total $\mathrm{N}$ of signatures or scientific contributions by $\mathrm{N}$ of documents published

Research impact: absolute $\mathrm{N}$ of citations received by documents on WoS, and mean citations per paper

Social network indicators

Density: $\mathrm{N}$ of links established between authors in the research community as a proportion of the maximum $\mathrm{N}$ of links that are theoretically possible

Betweenness: proportion of all geodesics between pairs of other communities that include this community

Cut-points

Bibliometric indicators on research performance and collaboration

Scientific production: $\mathrm{N}$ of documents

Collaboration: co-author index and rank in the order of signatures (first and last authors)

Research impact: $h$-index, calculated as maximum

( $h$ ) $\mathrm{N}$ of articles that have received $\geq h$ citations each

Social network embeddedness indicators

(a) Structural dimension

Betweenness: proportion of all geodesics between pairs of other vertices that include this vertex

Closeness: geodesic distance of one node to all other nodes in the network

Clustering coefficient (CC): measure of the average ties established among adjacent nodes of a vertex

Constraint: proportion of single contacts of a vertex relative to mutually related contacts

\section{(b) Relational dimension}

Degree: $\mathrm{N}$ of links that a node (author) has with other nodes
Characterize research activity in absolute and relative terms (in relation to $\mathrm{N}$ of authors in the research community)

Establishes average $\mathrm{N}$ of authors who have participated in the group of analyzed documents

Characterizes impact of research activity in absolute and relative terms (in relation to the total documents published by the research community)

Reflects the degree of connection or compactness of the research community

Characterizes the position of a community in the network, determining the extent to which that community acts as an intermediary or controls the information flow between other communities

Reflects absolute volume of scientific activity generated

Measures extension of cooperative practices (coauthor index) and degree of contribution or leadership in research (author order)

One of the most common indicators to evaluate research performance, combining productivity and impact of publications

Characterizes the position of an author in the network, determining the extent to which they act as intermediaries or control the information flow between other authors

Characterizes the position of an author in the network, determining their proximity to other authors in the network

Measures how integrated the researcher is in a cluster or research community; high values show denser relationships and greater cohesion and integration in community

Determines redundancy of collaboration ties established by an author; high values show denser ties among collaborators; this would limit the novel contacts that the author contributes to the network

Assesses the researcher's cooperative links (with other collaborating authors) 
Table 2 (continued)

\begin{tabular}{|c|c|}
\hline Definition & Scope of indicator(s) \\
\hline $\begin{array}{l}\text { Weighted degree: total sum of all established co- } \\
\text { authorship links }\end{array}$ & $\begin{array}{l}\text { Absolute expression of the extent of cooperative } \\
\text { practices, independently of their intensity and the } \mathrm{N} \\
\text { of authors with whom they collaborate }\end{array}$ \\
\hline $\begin{array}{l}\text { Average weighted degree (strength of ties) (AWD): } \\
\text { coefficient between the N of co-authorships (incl. } \\
\text { repeated collaborations) and the degree }\end{array}$ & $\begin{array}{l}\text { Relative indicator measuring the mean intensity of } \\
\text { established co-authorship ties }\end{array}$ \\
\hline $\begin{array}{l}\text { Connectivity degree (CD): N nodes connected to } \\
\text { the largest component through the cut-point }\end{array}$ & $\begin{array}{l}\text { Assesses the extent to which the cut-point facilitates } \\
\text { the integration of new nodes/agents in the network }\end{array}$ \\
\hline \multicolumn{2}{|l|}{ (c) Cognitive dimension } \\
\hline $\begin{array}{l}\text { Geographic (country): determined according to the } \\
\text { author's institutional affiliation }\end{array}$ & $\begin{array}{l}\text { Enables analysis and characterization of the geo- } \\
\text { graphic dimension in relation to the collaboration } \\
\text { process }\end{array}$ \\
\hline $\begin{array}{l}\text { 1st publication year }\left(1^{\text {st }} \mathrm{PY}\right) \text { : corresponding to the } \\
\text { author's first published document indexed in the } \\
\text { WoS }\end{array}$ & $\begin{array}{l}\text { Provides information on the author's level of experi- } \\
\text { ence and the stage of their professional career }\end{array}$ \\
\hline $\begin{array}{l}\text { Topic (WoS category): main WoS subject category } \\
\text { of the documents analyzed }\end{array}$ & $\begin{array}{l}\text { Elucidates the author's main research specialty or } \\
\text { field }\end{array}$ \\
\hline $\begin{array}{l}\text { Thematic specialization index (TSI): percentage of } \\
\text { documents corresponding to the analyzed subject } \\
\text { area in relation to the total number of documents } \\
\text { published during the study period }\end{array}$ & $\begin{array}{l}\text { Assesses the author's degree of specialization or } \\
\text { concentration of their research efforts }\end{array}$ \\
\hline
\end{tabular}

WoS: Web of Science

Table 3 General description and structural measures of the co-authorship network for research on ventilator-associated pneumonia

\begin{tabular}{ll}
\hline Indicator & Value \\
\hline Number of vertices & 8487 \\
Number of lines & 50,164 \\
$=1$ & 45,301 \\
$\neq 1$ & 4863 \\
Average degree & 11.82 \\
Network degree centralization & 0.027 \\
Density & 0.001 \\
Average distance & 5.22 \\
Largest distance & 16 \\
Watts-Strogatz clustering coefficient & 0.932 \\
Modularity & 0.917 \\
Number of components & 590 \\
Size of the largest component & 4611 \\
$\%$ participating authors & $54.33 \%$ \\
\hline
\end{tabular}

\section{Main research sub-network and research communities}

To identify the research clusters or communities that make up the main research subnetwork of the area, we processed 3238 co-author relationships that were repeated at least three times, generating a sub-graph composed of 586 authors. The largest component 
of this sub-graph (main research sub-network) contains 278 interrelated authors and 30 cut-points, labeled with their names and surnames (Fig. 1). Running the clustering algorithm showed the existence of 17 research communities, with the most prominent comprising 51 authors (M. Klompas being the author of reference) and two other communities of 35 authors each (with J. Rello and A. Torres serving as the references). Other communities - also prominent but with fewer authors - surround these large ones, while the periphery shows some smaller communities. Among these, a 9-member community headed by M.H. Kollef acts as a bridge between the two largest communities in the network, as does a 13-member community whose most prominent author is J. Chastre and which also stands out for its central position in the network. The analysis of this sub-graph shows that many cut-points, in addition to connecting different research clusters or communities, also present a high degree of integration in one of the different communities in which they participate, maintaining collaborative ties with most of the authors therein. (Fig. 1).

The aggregate analysis of the research communities (Fig. 2) reveals more clearly how the research communities of M.H. Kollef (community 4) and J. Chastre (community 6) are central references for the network. Despite their small size, they show the highest centrality (Table 4 ) based on their betweenness values ( 0.43 and 0.40 , respectively). This aspect is favored by the fact that J. Chastre's community acts as the sole bridge linking four other communities, while M.H. Kollef's community is connected to the highest number of other communities $(N=6)$ by means of this cut-point. Moreover, the intercommunity links between those that present high centrality are generally characterized by $\mathrm{N}: \mathrm{N}$ relationships (various interrelated authors from both communities), with the exception of community 4, where M.H. Kollef is linked to the rest of the communities with $1: \mathrm{N}$ relationships. At the periphery of the network, intercommunity links are generally through 1:1 ties.

With regard to the intensity of the intercommunity links, the average strength of ties (3.69) between communities is sensibly lower than that shown by cut-points (4.22) and by authors making up the main research focus (3.93). Table 4 shows the bibliometric and network indicators for the 17 research communities identified. In addition to the

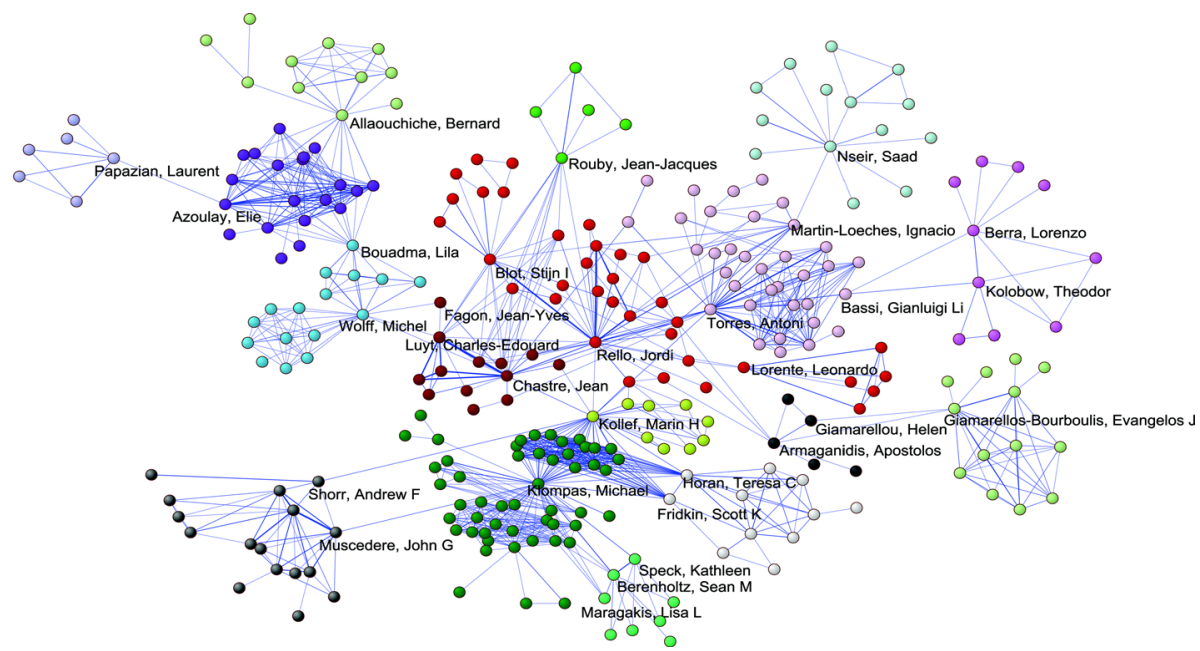

Fig. 1 Largest component (main research sub-network) of the co-authorship network on ventilator-associated pneumonia (strength of ties $\geq 3$ ). The research communities are identified by the color of the nodes; cut-points are labelled. (Color figure online) 


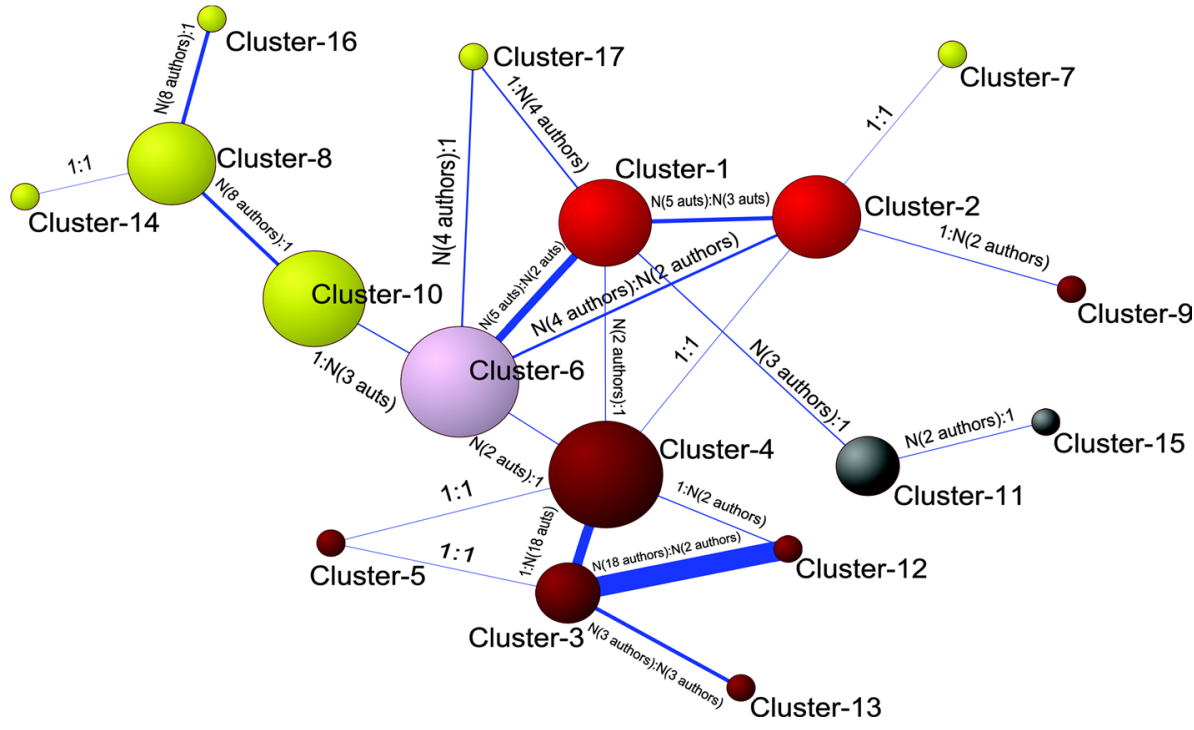

Fig. 2 Research communities identified in the co-authorship network on ventilator-associated pneumonia. The color of the nodes represents the main country of the authors that make up the communities

differences in scientific production and the higher degree of collaboration shown by some of them, one of the most significant aspects is the high average number of citations per document achieved by communities 12 (T.C. Horan's and S.K. Fridkin's community), 3 (M. Klompas), 5 (J.G. Muscedere /A.F. Shorr), and 17 (J.J. Rouby).

Consistent with the observations on centrality described above, the social network indicators show a notable polarization between some communities that present high density (39\% to $67 \%$ ) compared to other communities with moderate to low densities (10\% to $33 \%)$.

The division of researchers into different communities and the ties they have established between them largely respond to geographical factors. Thus, communities 3,4 , 12 , and 13 are made up primarily of U.S. authors; 5, by Canadian authors; 8, 10, 14, and 16, by French authors; 1 and 2, by Spanish authors; and 11 and 15, by Greek authors. It is also significant that community 6 , which shows the highest levels of intermediation, is also the most heterogeneous, with authors from the USA and several different European countries (Fig. 2). It is also possible to establish different thematic foci of VAP research. While most communities are interested in the clinical approach in intensive care units $(1,2,5,6,7,8,9,14$, and 16), some address epidemiological concerns $(3,4,10,11,12$, and 13) or microbiological aspects of the disease (15 and 17).

Participation in the main research sub-network (largest component of the sub-graph generated, bringing together the most intense collaboration ties) is decisive in terms of productivity and citation. In that sense, authors who are members of this research component present a mean of $6.68 \pm 6.48$ documents per author and $38.37 \pm 77.91$ citations per document, compared to a mean of $1.3 \pm 1.03$ documents per author and 


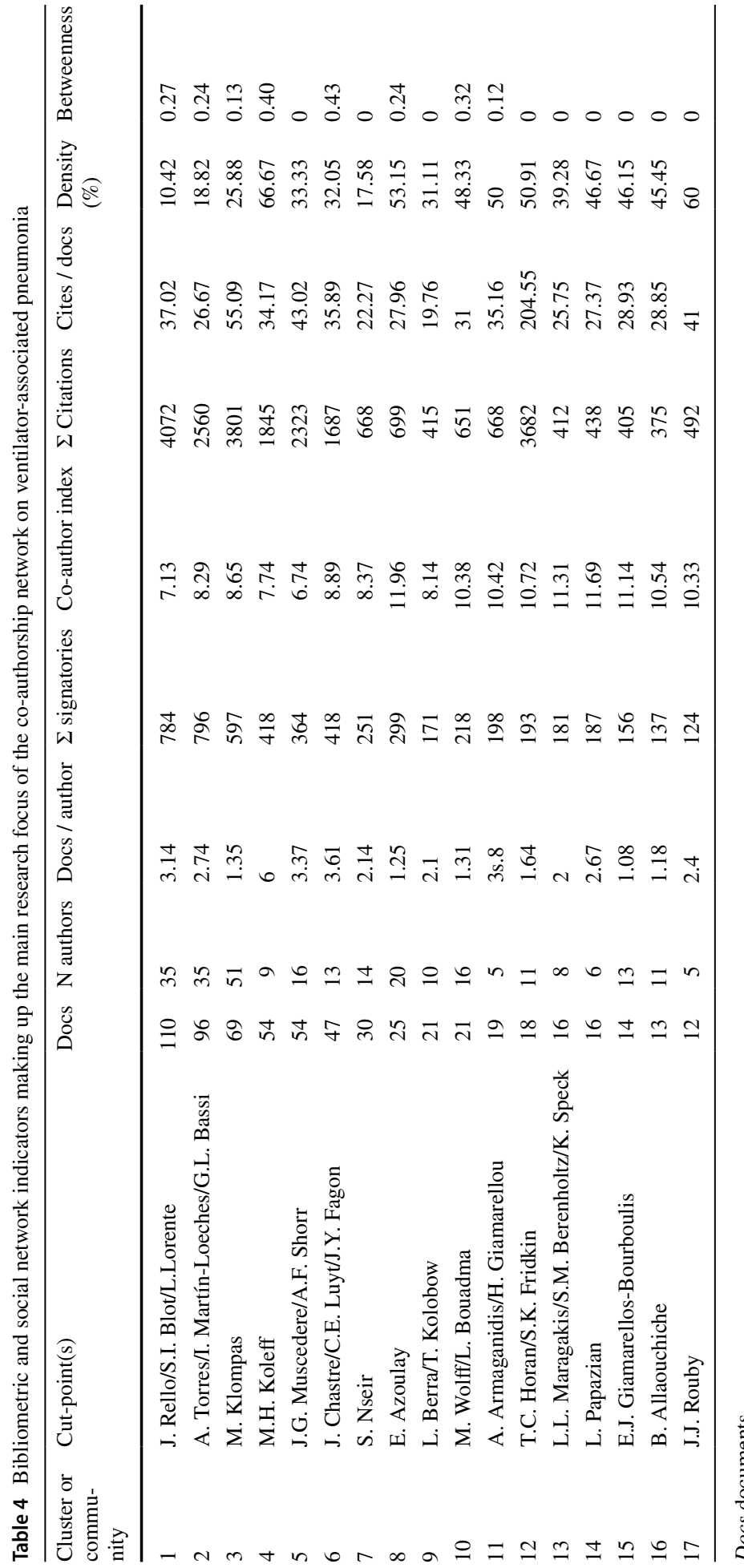


$22.03 \pm 48.05$ citations per document among the total population of authors in the area analyzed.

\section{Cut-points: research performance and network analysis}

With regard to the differential features of the cut-points and their scientific production (30 authors participating on 360 documents) relative to the rest of the researchers in the main research sub-network (248 authors participating on 438 documents), the cut-points presented much higher levels of productivity (mean $17.93 \pm 12.93$ versus $5.31 \pm 3.20$ documents per author). However, there were no differences in terms of the degree of collaboration and the mean citations per document between these two groups of authors $(8.12 \pm 6.02$ authors and $42.28 \pm 87.46$ citations per document with contributions from cut-points, versus $8.23 \pm 5.94$ authors and $40.05 \pm 82.34$ citations per document with contributions from the rest of the authors in the main research sub-network). Cut-points were the lead authors on $31.94 \%(N=115)$ of the documents in which they participated, and the last authors on $58.05 \%(N=209)$ of the papers. Among the rest of the authors in the main research sub-network, these values were $41.32 \%(N=181)$ and $38.81 \%$ $(N=170)$, respectively.

Regarding the measures of centrality, betweenness was the only variable showing substantial differences between cut-points and the rest of the authors making up the main research sub-network (0.02489447 versus 0.00034964$)$. The other indicators of centrality measured (degree and closeness) were quite similar between groups. In terms of indicators of cohesion, the cut-points showed much lower clustering coefficients $(0.39 \pm 0.24)$ compared to the rest of the authors in the main research sub-network $(0.91 \pm 0.19)$. Finally, there were also important differences in the constraint variable between cut-points $(0.27 \pm 0.14)$ and other authors $(0.59 \pm 0.3)$.

Table 5 shows the bibliometric and network embeddedness indicators for the 30 cutpoints identified. The most significant aspect is that the five most productive authors (J. Rello, M.H. Kollef, A. Torres, M. Klompas, and J. Chastre) occupy the top spaces in nearly all rankings based on bibliometric, structural, and relational indicators. Their exact positions alternate depending on the indicator considered. Moreover, some other cut-points also stand out with regard to isolated indicators (like T.C. Horan and S.K. Fridkin in degree, M. Wolff in betweenness, and S. Nseir in constraint). The analysis of the cognitive dimension in the co-authorship network shows that cut-points stand out in several aspects. They are authors with a long research career behind them, with most having begun their activities several decades prior. Likewise, they are characterized by their diversified participation in different topic areas or lines of research; for the most part, their papers in the area of VAP constitute only a fraction of their overall body of publications on the WoS (mean $18.38 \pm 1.22$ documents).

With regard to the role that cut-points play in promoting connectivity and the structure of their ego-networks, they show heterogeneous characteristics both in intercommunity ties (as some maintain N:N relationships, while others tend to participate in 1:1 relationships) and in their connectivity degree (with some authors like M.H. Kollef or M. Klompas whose elimination would produce an enormous fragmentation in the largest component, compared to others who tie together fewer authors). The degree of integration in their research community also varies. Authors like S.K. Fridkin, T.C. Horan, E. Azoulay, and C.E. Luyt present high clustering coefficients. Others stand out more 


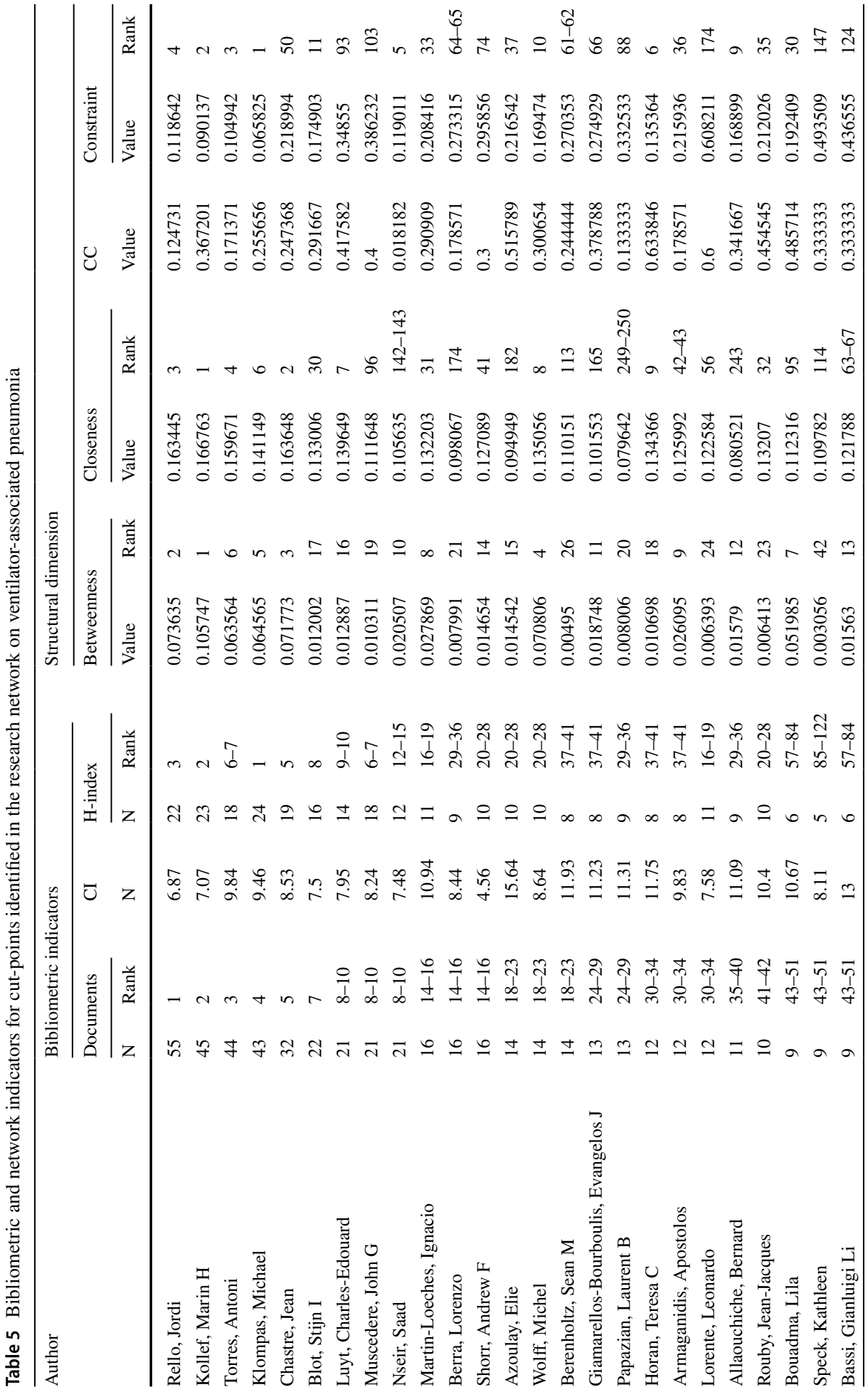




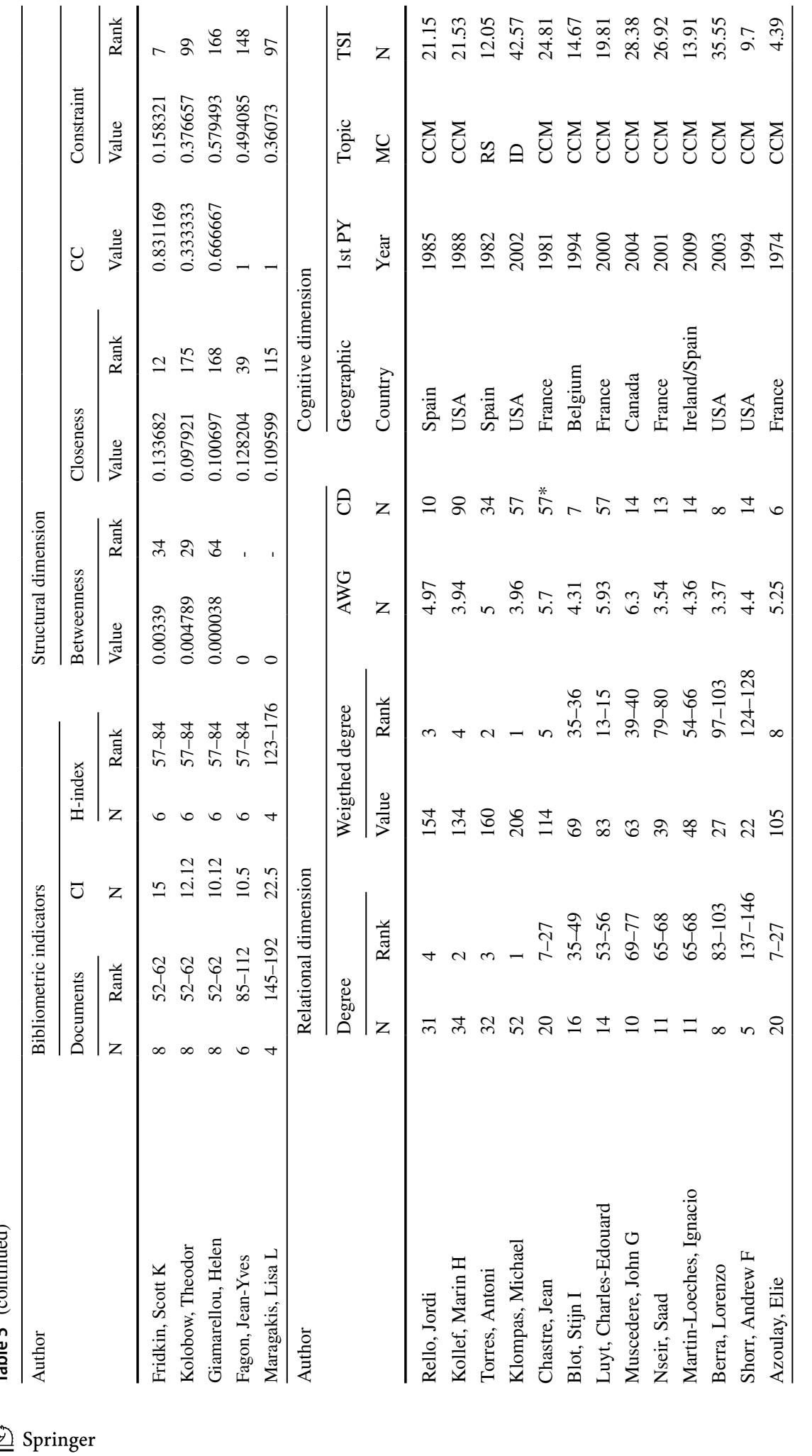




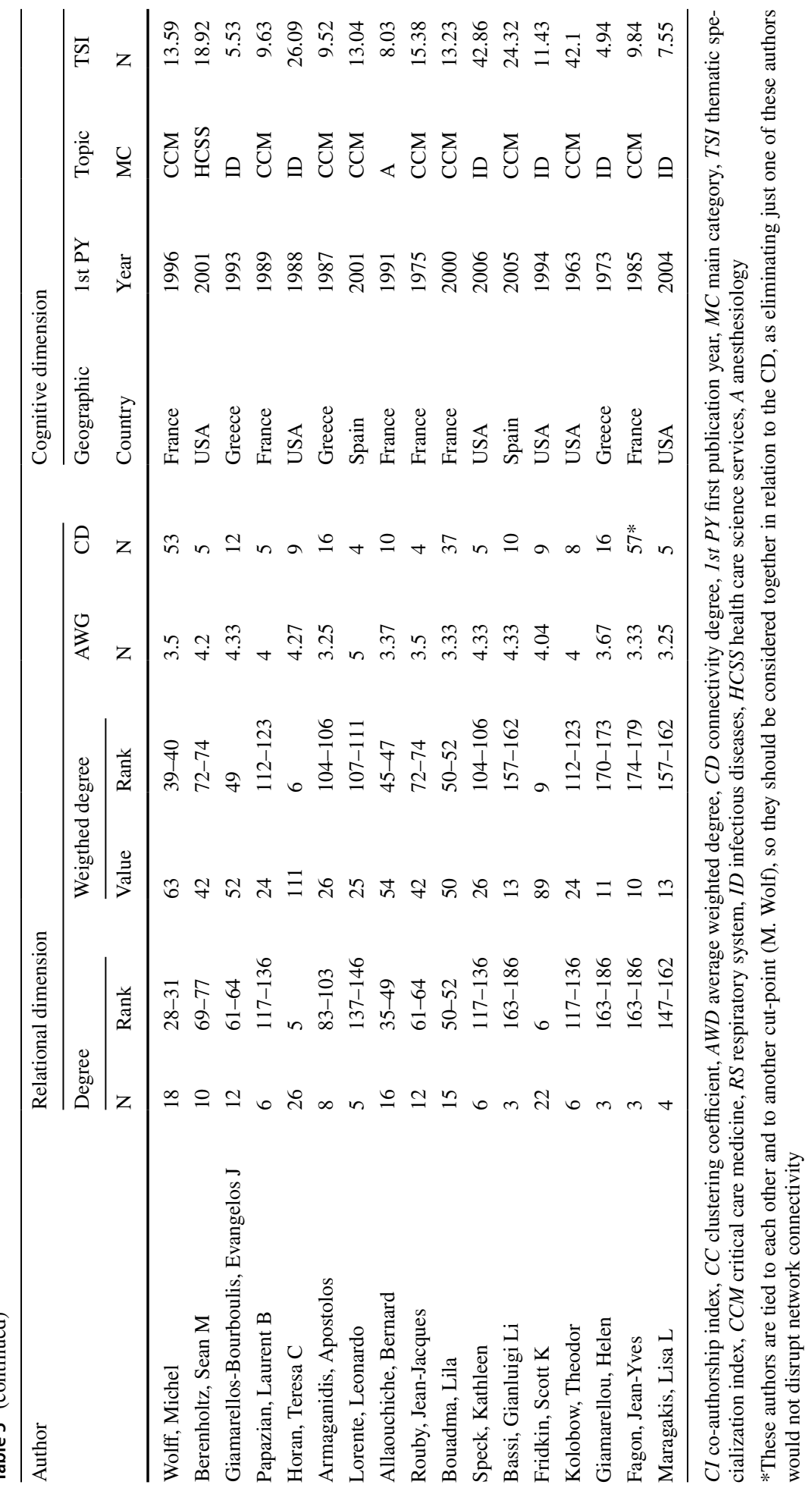


for their role as brokers, or internal cut-points, in their own communities, as they have established more non-redundant ties. M. Klompas is the main reference in that sense, as he is at the center of three prominent sub-communities that would not otherwise be connected. Other notable brokers include M. Wolff, S.I. Blot, L. Lorente, and S. Nseir.

The analysis of the correlations between the research performance indicators and the social network measures (Table 6) show that in cut-points, intermediation and degree are closely associated with research performance, while for the rest of the authors, average strength of ties is the most intensely correlated variable with scientific production and impact, as measured by the $h$-index. Constraint presents an intense correlation with indicators of research performance among cut-points, although the direction is negative: research performance increases with the establishment of non-redundant ties.

\section{Discussion}

\section{VAP co-authorship network as a small world}

The co-authorship network for VAP has the characteristics of a small-world network, that is, it shows substantial local clustering and short pathways between actors in different clusters. This is evidenced by the average distance (5.22) and the high modularity (0.92) (Liu and Xia 2015; Watts and Strogatz 1998). Although the largest component includes more than half the authors (54.33\%) writing on the topic, this level of integration is lower than that observed in other areas of biomedical research, where values of $70 \%$ to $95 \%$ have been observed (González-Alcaide et al. 2016; Vanni et al. 2014; Yu et al. 2013). This, together with the elevated index of transience (80.54\%)-higher in the VAP field than in areas like psoriasis (González-Alcaide et al. 2015), and the fact that only authors from the USA, Canada and some European countries participate in the main research sub-network, indicates some compartmentalization and dispersion in the research area analyzed. Factors that may influence this phenomenon include closer local or national ties in clinical research (González Alcaide et al. 2012) or the tendency of a large part of the scientific community to investigate VAP together with other topics and lines of research. Furthermore, the largest component could be considered the seat of the main activity of a research area (Kumar and Markscheffel 2016), making membership fundamental in terms of scientific performance. Our findings support this hypothesis, both in terms of productivity and in research impact, suggesting the necessity of promoting collaboration through international multicenter studies that involve as many researchers as possible, particularly in areas outside of North American and Europe (Leydesdorff and Wagner 2008). The relevance that growth in the largest component has to other aspects is also worth noting, as this can promote development of an interdisciplinary field of knowledge (Liu and Xia 2015) and translational research (Long et al. 2013a, b).

Geographical proximity stands out as the most prominent factor favoring collaborative ties and the formation of research communities about VAP, as observed previously (Arroyo Moliner et al. 2017; Katz 1994). However, the VAP community with the greatest centrality and a high level of scientific performance is made up of an international group of researchers, which highlights the relevance of promoting international collaborations. Another noteworthy finding is that some of the groups with the best scientific performance are also among the smallest. They are situated on the periphery of the main research sub-network, although with direct collaborative ties to authors and communities of reference, along with 


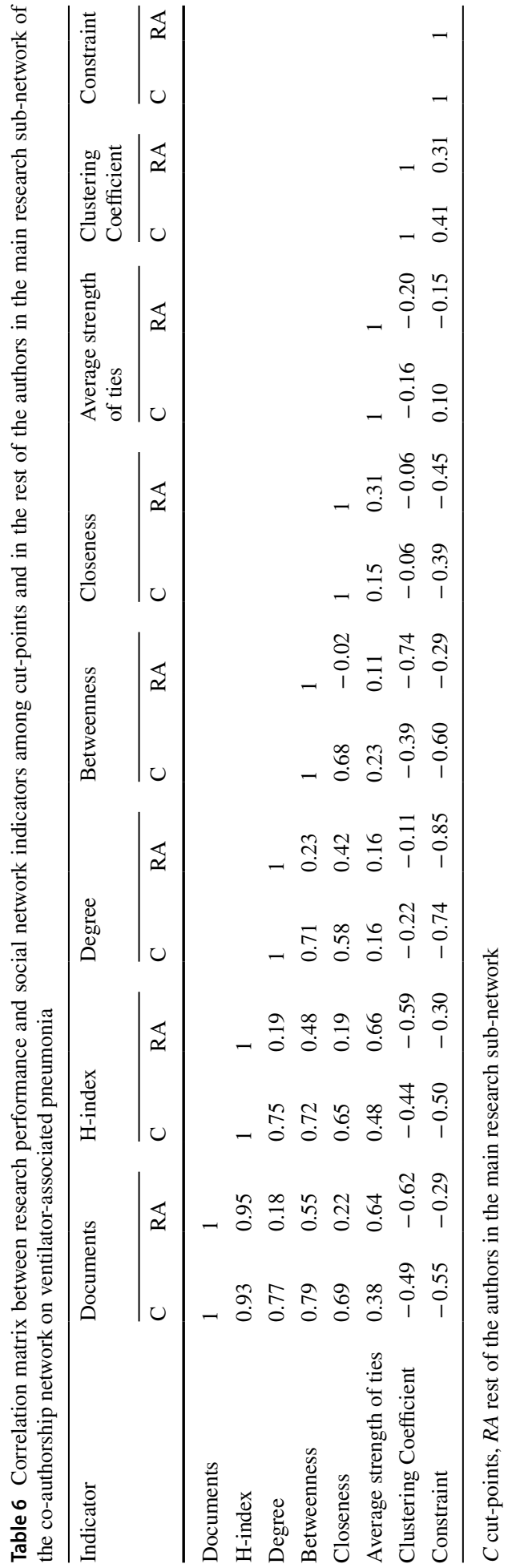


high connectivity degrees and centrality. This indicates that it is not necessary to be integrated in a large research community to achieve research excellence. Rather, researchers can investigate specific aspects of interest to the discipline, establishing sporadic collaborative ties with the mainstream investigator of the area.

\section{Cut-points and research performance}

As reported elsewhere (Cardillo et al. 2006; Li-Chun et al. 2006), a small group of authors (J. Rello, M.H. Kollef, A. Torres, M. Klompas, and J. Chastre in the present study) occupy all of the top places in the rankings generated based on both bibliometric and network embeddedness indicators. The presence of these elite actors in favored locations are thus a feature of co-authorship networks, as these small-world networks generate inequality and stratification among their nodes. Li-Chun et al. (2006) argue that the development of this elite group should not be seen as negative, as the researchers are far from closed and isolated groupings. Instead, they serve as active hubs promoting diversity, communication and integration into research communities. Our analysis supports this argument; the same occurs with the authors mentioned who are integrated in the main research sub-network of this study.

The cut-points play a key role in scientific co-authorship networks. As Azondekon et al. (2018) cautions, the elimination of these figures-less than $1 \%$ of the authors belonging to the network-would result in its collapse. While cut-points present higher intermediation values than other authors, this feature is not exclusive to them, and there is no single centrality measure that allows the precise identification of these agents. In a specific analysis of the degree of the nodes relative to the composition and cohesion of the network's giant component, Liu and Xia (2015) reported that the nodes with the highest degrees are not necessarily the bridges or hubs for establishing global connectivity. On the contrary: the giant component basically remains connected even with the removal of the high-degree nodes. Borgatti (2006b), aware that nodes with high centrality and cut-points have different properties (and that the same nodes do not necessarily have both) signaled the need to combine different criteria to identify a field's key players. These should be identified separately, as they include both the set of nodes maximally connected to all other nodes (i.e. with high centrality) and the set of nodes whose removal would result in a residual network with the least possible cohesion (cut-points).

In line with other previous studies (Abbassi et al. 2011; Uddin et al. 2012), we confirmed the existing correlation between measures of centrality, particularly those based on the structural dimension of social capital, and research performance. In our study, betweenness was the indicator with the strongest association to research performance, in terms of both productivity and impact ( $h$-index). This association, along with the association that both degree and closeness had with research performance, was much more intense in cut-points than in other authors. These observations are concordant with those made by Cainelli et al. (2015) in a co-authorship network analysis of Italian economists. These authors concluded that a high degree of centrality (and betweenness more so than closeness) is correlated with an increase in scientific productivity, highlighting that bridges that connect two nearly separated parts of a network favor scientific productivity even more. In the area of library and information science, Li et al. (2013) and Yan and Ding (2009) also reported that centrality measures, and especially betweenness, showed significant correlations with citation counts. For their part, in the area of 
steel structures, Uddin et al. (2012) determined that betweenness and degree were the two centrality indicators that were most closely associated with citations in scientific co-authorship networks. The most generalized interpretation of this association is based on social capital as generated by structural holes, which would be greater in authors serving as network bridges. To varying extents, this quality is common to all cut-points (Burt 1992).

In contrast, other studies such as the one by Bordons et al. (2015) analyzing Spanish co-authorship research networks in the area of Nanoscience, Pharmacology and Statistics reported that the variables most strongly related to research performance are degree and average strength of ties, both indicators associated with the relational dimension of social capital. Bordons and colleagues speculated that authors presenting high values for these indicators benefit from the knowledge and skills of a greater number of collaborators, and that the maintenance of stable ties nurtures a climate of trust and exchange of resources, among other aspects than can favor consolidated cooperative practices (Abbasi et al. 2011; Badar et al. 2013). Badar et al. (2013), studying co-authorship research networks in the field of chemistry in Pakistan, determined that research performance is positively associated with both degree and closeness centrality, but not intermediation. The authors interpreted this finding to reflect the relatively high cost that establishing non-redundant collaborative ties incurs, as well as the domestic orientation of the collaborations.

In addition to a more intense association between scientific performance and structural dimension indicators among cut-points, we also observed important differences between cut-points and other authors in the network in terms of cohesion indicators. In cut-points, research performance shows a strong association with constraint, while for other authors it is more related to the average strength of ties and the clustering coefficient.

Without a doubt, these differences respond to two different models of research activity (Hayat and Lyons 2017; Jansen et al. 2010). The brokerage style characterizing cut-points is associated with researchers who have the capacity to identify opportunities, seek innovation, mediate, and integrate different perspectives, that is, authors who can exploit the strategic value of brokerage positions or structural holes (Burt 2004). In that sense, Wagner et al. (2015) analyzed the co-authorship networks of 68 Nobel Laureates in Physiology and Medicine between 1969 and 2011, highlighting the very different patterns followed by this group compared to others. The results suggested that having more non-redundant connections and facilitating links between different communities (brokerage style) creates better opportunities for incorporating new ideas, methods, and technologies into one's work, in short, offering a crucial advantage in terms of social capital (Burt 1992).

On the other hand, stability style or team style prioritizes stable collaborations and participation in cohesive group projects. This style can also be associated with outstanding scientific performance (Abbasi et al. 2011), and it is favored by researchers who seek trusted collaborators who complement their own strengths and share the same vision and working style, among other aspects (Hara et al. 2003).

As described by Jansen et al. (2010), these styles can complement each other, and both favor the development of research. Brokerage style can be more beneficial when aiming to synthesize diverse areas of knowledge and ideas, but stability style, with its intense collaborative ties and the trust developed between partners, can help researchers drill down into a subject for more in-depth understanding.

We did not observe differences in mean citations per document between cut-points and other authors in the main VAP research sub-network. This finding contrasts with those from other studies, which reported that serving a network brokerage role is an important 
determinant of citation degree (Heinze and Bauer 2007; Song et al. 2018). The explanation for this difference probably resides in the relative homogeneity of the research communities studied, which were prominent in the field and comprised authors that were characterized by a dual clinical/academic affiliation and a high intensity of collaboration ( $\mathrm{Li}$ et al. 2013; Liao 2011). On the other hand, the researchers who did not belong to the main subnetwork presented substantial differences in their citation degree.

Cut-points did have an advantage in indicators associated with longer and more consolidated research careers, like the $h$-index. Moreover, their signatures were more likely to anchor the author lists on their papers, which is associated with the direction and supervision of research works (Avula and Avula 2015; Baerlocher et al. 2007). That fact, plus the very early dates when they first published, suggest that cut-points are often senior researchers with a long and consolidated academic trajectory, who are characterized by their broad research interests and activities. The studies investigating the reasons why these scientific agents occupy such a relevant position in their networks also point to personal factors. For example, in a longitudinal analysis of researchers in nano-science and technology, Heinze and Bauer (2007) highlighted the importance of individuals' creativity-their capacity to do novel, original, and valuable work - and their communication and networking skills, which allow them to connect peers and bring together groups. Liu et al. (2015) recognized the relevance of experience and time in the field, but they also held that cut-points' role is partially a function of their leadership, understood as a set of personal skills that they learn and develop over the years, for instance, the capacity to orient others' efforts towards a common goal and to their publications. Other leadership skills were the ability to acquire more information and resources, integrate these into the workflow, and interact with others; personal charisma was also a quality attributed to leaders. In their study, Kumar and Markscheffel (2016) reported that the authors with the highest centrality values were often institutional heads or directors of prominent research programs. They had frequently been awarded or otherwise recognized for their research work and belonged to associations or committees of reference in their research discipline. Our analysis of cut-points' academic status and professional careers confirms that the authors with the highest values of centrality and connectivity degree are senior researchers who serve as the heads of teaching departments, clinical units, and research groups or networks. They hold different awards accumulated over their academic and research careers. In the case of some cut-points on the periphery of the main research focus, they are characterized by a shorter and more mobile scientific career, and a more recent incorporation in their current institution. Thus, although these authors are prominent agents in their field, they are also immersed in a process of consolidating and expanding their collaboration networks and working groups.

\section{Brokerage styles in cut-points}

Although the brokerage role predominates over cohesion among cut-points, in consonance with González-Brambila's (2013) conclusions about the effect embeddedness has on research output and citation, our results provide more detail on this point. Moreover, we note that this situation is inverted among the rest of the authors in the main research sub-network, among whom cohesion and relational embeddedness are more pronounced than the structural dimension. Thus, one of the most significant results of the present study is that the cut-points are researchers who have the positive features associated with both the main theories on social capital. On the one hand, they enable 
interconnections between different communities and groups (thanks to their role in plugging the structural holes). On the other, they also present a high degree of cohesion when analyzing the individual ties that they establish with different communities in which they participate. In this way, they can also take advantage of the benefits of their participation in these cohesive structures and in the relational dimension. Thus, the cut-point figure would respond to the ego-network typology of complex structures, described by Rumsey-Wairepo (2006) and Kuzhabekova (2011). The fact that the cutpoints' ego networks presented very heterogeneous structures probably reflects differences within the brokerage styles and research collaboration patterns of this group. The literature describes several concepts related to specific differential features or properties of some nodes, which permit network connectivity (Long et al. 2013c). These concepts can frame a more precise analysis of the role played by cut-points or brokers (as generic concepts) in favoring the interconnection between different research communities:

- The concept of bridge is understood as a node that acts as an intermediary for contacts with another community (nodes that participate in 1:1 relationships to bridge the structural hole between two clusters). This concept points to the relevance of the notion of weak ties proposed by Granovetter (Valente and Fujimoto 2010), which could arise from incipient contacts between researchers or sporadic ties nested within a research project, among other origins. This would be the case of some of the peripheral research communities identified in the present study, for example, the communities of S. Nseir, L. Papazian, L. Berra, and A. Armaganidis. These cut-points present the lowest clustering coefficients among all the cut-points, while their communities show the lowest densities. Such findings are consistent with the characteristics of newer research communities.

- The concept of gatekeeper, on the other hand, refers to the control of information exercised by some nodes (Cranefield and Yoong 2013). For example, 1:N relationships bridge the structural hole between the cut-point's cluster and an outside community. These nodes have the capacity to decide which information to share or use in their community from all the multiple contacts that they have established with researchers from other communities. M.H. Kollef exemplifies the figure of gatekeeper in our study, a role linked with Burt's notion of exploiting the advantageous position in the network through structural holes (Burt 1992). However, it would be an over interpretation to conclude that gatekeepers reach this position deliberately. Rather, it could be the natural result of working skills or styles that differ from those of other researchers, allowing them to act as leaders and coordinators, to identify new lines of work, to serve as mediators for resolving conflicts, or to integrate specialized information that comes to their attention from different sources (Gray 2008; Wagner et al. 2015).

- A structural fold would be a node that functions as a common agent in two overlapping or cohesive structures (Vedres and Stark 2010), through N:N relationships. In our study, these cut-points would include M. Klompas, B. Allaouchiche, L. Bouadma, and A. Torres, who all participate in highly dense communities. The simplest interpretation explaining this pattern would be that these investigators simultaneously participate in two or more groups or lines of research.

- Finally, boundary spanners are the most difficult to identify, as this would require additional information from that available based on co-authorships alone. These nodes would bridge the structural hole between two clusters that, for one reason or another, are separated by a conceptual boundary (Tushman 1977). In our study, the cut-points with this role would be those connecting authors from different institutions or coun- 
tries (J. Chastre, M.H. Kollef, J. Rello, and M. Wolff), but other aspects could also be considered under this rubric, for example cut-points that link different disciplines, specialties, research approaches, etc., with the essential role of fostering innovation and knowledge translation (Long et al. 2013c).

\section{Conclusions, limitations, and future lines of work}

Our results show that cut-points, in addition to being characterized by their essential role in the scientific co-authorship network analyzed, fostering overall connectivity and cohesion and contributing social capital to the network, also present important differential features in relation to other researchers. Notable characteristics are their higher scientific production and $h$-index. Moreover, although their role in filling structural holes is predominant, many of these authors also present a high degree of cohesion. Given the above, and to the extent that they integrate the two main mechanisms of generating social capital described in the literature, cut-points can be considered key players whose role is an essential impetus in research and the cognitive institutionalization of a discipline. Some cut-points situated on the periphery of the giant component may emerge later as key actors/players, as long as they maintain and increase their roles of connectivity, their social capital in filling structural holes, and at the same time their participation in different cohesive network structures. In network analysis, it is important to differentiate between authors who serve as cut-points and other researchers in the network (for example, those who stand out only as central actors in measures like intermediation, degree, and closeness) or who merely play a brokerage role or participate in cohesive structures.

The main limitation of our study is its focus on a single case. Thus, future studies should confirm the implications of our results and conclusions. Researchers can also perform an in-depth analysis to interpret the indicators and roles played by cut-points, using qualitative methods based on questionnaires or interviews with this group of authors.

\section{References}

Abbasi, A., Altmann, J., \& Hossain, L. (2011). Identifying the effects of co-authorship networks on the performance of scholars: A correlation and regression analysis of performance measures and social network analysis measures. Journal of Informetrics, 5(4), 594-607. https://doi.org/10.1016/j. joi.2011.05.007.

Abbasi, A., Chung, K. S. K., \& Hossain, L. (2012). Egocentric analysis of co-authorship network structure, position and performance. Information Processing and Management, 48(4), 671-679. https://doi. org/10.1016/j.ipm.2011.09.001.

Adams, J. D., Black, G. C., Clemmons, J. R., \& Stephan, P. E. (2005). Scientific teams and institutional collaborations: evidence from US universities, 1981-1999. Research Policy, 34(3), 259-285. https://doi. org/10.1016/j.respol.2005.01.014.

Ahuja, G. (2000). Collaboration networks, structural holes, and innovation: A longitudinal study. Administrative Science Quarterly, 45(3), 425-455. https://doi.org/10.2307/2667105.

Arroyo Moliner, L., Gallardo-Gallardo, E., \& Gallo de Puelles, P. (2017). Understanding scientific communities: A social network approach to collaborations in Talent Management research. Scientometrics, 113(3), 1439-1462. https://doi.org/10.1007/s11192-017-2537-1.

Azondekon, R., Harper, Z. J., Agossa, F. R., Welzig, C. M., \& McRoy, S. (2018). Scientific authorship and collaboration network analysis on malaria research in Benin: Papers indexed in the web of science (1996-2016). Global Health Research and Policy, 3, 11. https://doi.org/10.1186/s41256-018-0067-x.

Avula, J., \& Avula, H. (2015). Authors, authorship order, the moving finger writes. Journal of Indian Society of Periodontoly, 19(3), 258-262. https://doi.org/10.4103/0972-124X.145782. PMID: 26229263. 
Baerlocher, M. O., Newton, M., Gautam, T., Tomlinson, G., \& Detsky, A. S. (2007). The meaning of author order in medical research. Journal of Investigative Medicine, 55(4), 174-180. https://doi. org/10.2310/6650.2007.06044.

Badar, K., Hite, J. M., \& Badir, Y. F. (2013). Examining the relationship of co-authorship network centrality and gender on academic research performance: The case of chemistry researchers in Pakistan. Scientometrics, 94(2), 755-775. https://doi.org/10.1007/s11192-012-0764-z.

Bavelas, A. (1950). Communication patterns in task-oriented groups. Journal of the Acoustical Society of America, 22, 725. https://doi.org/10.1121/1.1906679.

Bordons, M., Aparicio, J., González-Albo, B., \& Díaz-Faes, A. A. (2015). The relationship between the research performance of scientists and their position in co-authorship networks in three fields. Journal of Informetrics, 9(1), 135-144. https://doi.org/10.1016/j.joi.2014.12.001.

Borgatti, S. P. (2006a). Centrality and network flow. Social Networks, 27(1), 55-71. https://doi. org/10.1016/j.socnet.2004.11.008.

Borgatti, S. P. (2006b). Identifying sets of key players in a social network. Computational \& Mathematical Organization Theory, 12(1), 21-34. https://doi.org/10.1007/s10588-006-7084-x.

Bourdieu, P. (1986). The forms of capital. In J. G. Richardson (Ed.), Handbook of theory and research for the sociology of education (pp. 241-258). New York: Greenwood.

Bozeman, B., Fay, D., \& Slade, C. P. (2013). Research collaboration in universities and academic entrepreneurship: The-state-of-the-art. Journal of Technology Transfer, 38(1), 1-67. https://doi.org/10.1007/ s10961-012-9281-8.

Burt, R. S. (1992). Structural holes: The social structure of competition. Cambridge: Harvard University Press.

Burt, R. S. (2004). Structural holes and good ideas. American Journal of Sociology, 110(2), 349-399. https ://doi.org/10.1086/421787.

Cainelli, G., Maggioni, M. A., Uberti, T. E., \& de Felice, A. (2015). The strength of strong ties: How coauthorship affect productivity of academic economists? Scientometrics, 102(1), 673-699. https://doi. org/10.1007/s11192-014-1421-5.

Cardillo, A., Scellato, S., \& Latora, V. (2006). A topological analysis of scientific coauthorship networks. Physica A: Statistical Mechanics and its Applications, 372(2), 333-339. https://doi.org/10.1016/j. physa.2006.08.059.

Coleman, J. S. (1988). Social capital in the creation of human capital. American Journal of Sociology, 94, S95-S120. https://doi.org/10.1086/228943.

Cranefield, J., \& Yoong, P. (2007). Interorganisational knowledge transfer: the role of the gatekeeper. International Journal of Knowledge and Learning, 3(1), 121-138. https://doi.org/10.1504/IJKL.2007.01260 4.

Doreian, P., \& Fujimoto, K. (2004). Identifying linking-pin organizations in inter-organizational networks. Computational and Mathematical Organization Theory, 10(1), 45-68. https://doi.org/10.1023/ B:CMOT.0000032579.62046.0b.

Freeman, L. C. (1979). Centrality in social networks: I. Conceptual clarification. Social Networks, 1(3), 215-239. https://doi.org/10.1016/0378-8733(78)90021-7.

Gilsing, V., Nooteboom, B., Vanhaverbeke, W., Duysters, G., \& van den Oord, A. (2008). Network embeddedness and the exploration of novel technologies: Technological distance, betweenness centrality and density. Research Policy, 37(10), 1717-1731. https://doi.org/10.1016/j.respol.2008.08.010.

González Alcaide, G., Valderrama Zurián, J. C., \& Aleixandre Benavent, R. (2012). The impact factor in non-English-speaking countries. Scientometrics, 92(2), 297-311. https://doi.org/10.1007/s1119 2-012-0692-y.

González-Alcaide, G., Park, J., Huamaní, C., Belinchón, I., \& Ramos, J. M. (2015). Evolution of cooperation patterns in psoriasis research: Co-authorship network analysis of papers in Medline (1942-2013). PLOS ONE, 10(12), e0144837. https://doi.org/10.1371/journal.pone.0144837.

González-Alcaide, G., Ramos, J. M., Huamaní, C., de Mendoza, C., \& Soriano, V. (2016). Human T-lymphotropic virus 1 (HTLV-1) and human T-lymphotropic virus 2 (HTLV-2): Geographical research trends and collaboration networks (1989-2012). Revista do Instituto de Medicina Tropical de Sao Paulo, 58, 11. https://doi.org/10.1590/S1678-9946201658011.

González-Brambila, C. N., Veloso, F. M., \& Krackhardt, D. (2013). The impact of network embeddedness on research output. Research Policy, 42(9), 1555-1567. https://doi.org/10.1016/j.respol.2013.07.008.

Granovetter, M. S. (1973). The strength of weak ties. American Journal of Sociology, 78(6), 1360-1380. https://doi.org/10.1086/225469.

Gray, B. (2008). Enhancing transdisciplinary research through collaborative leadership. American Journal of Preventive Medicine, 35(2 Suppl), S124-S132. https://doi.org/10.1016/j.amepre.2008.03.037. 
Hara, N., Solomon, P., Kim, S. L., \& Sonnenwald, D. H. (2003). An emerging view of scientific collaboration: Scientists' perspectives on collaboration and factors that impact collaboration. Journal of the American Society for Information Science and Technology, 54(10), 952-965. https://doi.org/10.1002/ asi.10291.

Harary, F., Norman, R., \& Cartwright, D. (1965). Structural models: An introduction to the theory of directed graphs. New York: Wiley.

Hayat, T., \& Lyons, K. (2017). A typology of collaborative research networks. Online Information Review, 41(2), 155-170. https://doi.org/10.1108/OIR-11-2015-0368.

Heinze, T., \& Bauer, G. (2007). Characterizing creative scientists in nano-S\&T: Productivity, multidisciplinarity, and network brokerage in a longitudinal perspective. Scientometrics, 70(3), 811-830. https://doi.org/10.1007/s11192-007-0313-3.

Jansen, D., von Görtz, R., \& Heidler, R. (2010). Knowledge production and the structure of collaboration networks in two scientific fields. Scientometrics, 83(1), 219-241. https://doi.org/10.1007/s1119 2-009-0022-1.

Jones, B. F., Wuchty, S., \& Uzzi, B. (2008). Multi-university research teams: Shifting impact, geography, and stratification in science. Science, 322(5905), 1259-1262. https://doi.org/10.1126/scien ce. 1158357 .

Katz, J. S. (1994). Geographical proximity and scientific collaboration. Scientometrics, 31, 31-43. https ://doi.org/10.1007/BF02018100.

Kumar, S. (2015). Co-authorship networks: A review of the literature. Aslib Journal of Information Management, 67(1), 55-73. https://doi.org/10.1108/AJIM-09-2014-0116.

Kumar, S., \& Markscheffel, B. (2016). Bonded-communities in HantaVirus research: A research collaboration network (RCN) analysis. Scientometrics, 109(1), 533-550. https://doi.org/10.1007/s1119 2-016-1942-1.

Kuzhabekova, A. (2011). Impact of co-authorship strategies on research productivity: A social-network analysis of publications in Russian cardiology. https://hdl.handle.net/11299/108109. Accessed 15 Jan 2020.

Leavitt, H. J. (1951). Some effects of certain communication patterns upon group performance. Journal of Abnormal and Social Psychology, 46(1), 38-50.

Leydesdorff, L., \& Wagner, C. S. (2008). International collaboration in science and the formation of a core group. Journal of Informetrics, 2(4), 317-325. https://doi.org/10.1016/j.joi.2008.07.003.

Li, E. Y., Liao, C. H., \& Yen, H. R. (2013). Co-authorship networks and research impact: A social capital perspective. Research Policy, 42(9), 1515-1530. https://doi.org/10.1016/j.respol.2013.06.012.

Liao, C. H. (2011). How to improve research quality? Examining the impacts of collaboration intensity and member diversity in collaboration networks. Scientometrics, 86(3), 747-761. https://doi. org/10.1007/s11192-010-0309-2.

Li-Chun, Y., Kretschmer, H., Hanneman, R. A., \& Ze-Yuan, L. (2006). Connection and stratification in research collaboration: An analysis of the COLLNET network. Information Processing and Management, 42(6), 1599-1613. https://doi.org/10.1016/j.ipm.2006.03.021.

Liu, C., Gan, B., \& Zhang, Y. E. (2015). Why "they" occupies the critical network positions? Management Decision, 53(1), 100-123. https://doi.org/10.1108/MD-04-2014-0186.

Liu, P., \& Xia, H. (2015). Structure and evolution of co-authorship network in an interdisciplinary research field. Scientometrics, 103(1), 101-134. https://doi.org/10.1007/s11192-014-1525-y.

Long, J. C., Cunningham, F. C., Carswell, P., \& Braithwaite, J. (2013a). Who are the key players in a new translational research network? Health Services Research, 13, 338. https://doi. org/10.1186/1472-6963-13-338.

Long, J. C., Cunningham, F. C., \& Braithwaite, J. (2013b). Bridges, brokers and boundary spanners in collaborative networks: A systematic review. BMC Health Services Research, 13, 158. https://doi. org/10.1186/1472-6963-13-158.

Long, J. C., Cunningham, F. C., Wiley, J., Carswell, P., \& Braithwaite, J. (2013c). Leadership in complex networks: The importance of network position and strategic action in a translational cancer research network. Implementation Science, 8, 122. https://doi.org/10.1186/1748-5908-8-122.

McFadyen, M. A., Semadeni, M., \& Cannella, A. A., Jr. (2009). Value of strong ties to disconnected others: Examining knowledge creation in Biomedicine. Organization Science, 20(3), 552-564. https:// doi.org/10.1287/orsc.1080.0388.

Nahapiet, J., \& Ghoshal, S. (1998). Social capital, intelectual capital, and the organization advantage. Academy of Management Review, 23(2), 242-266. https://doi.org/10.2307/259373.

Newman, M. E. J. (2001). Scientific collaboration networks. II. Shortest paths, weighted networks, and centrality. Physical Review E, 64(1), 016132. 
Newman, M. E. (2004). Who is the best connected scientist? A study of scientific coauthorship networks. In E. Ben-Naim, H. Frauenfelder, \& Z. Toroczkai (Eds.), Complex Networks. Lecture Notes in Physics (Vol. 650, pp. 337-370). Berlin: Springer.

Otte, E., \& Rousseau, R. (2002). Social network analysis: A powerful strategy, also for the information sciences. Journal of Information Science, 28(6), 441-453. https://doi.org/10.1177/016555150202800601.

Persson, O., Danell, R., \& Schneider, J. W. (2009). How to use Bibexcel for various types of bibliometric analysis. In F. Åström, R. Danell, B. Larsen, \& J. W. Schneider (Eds.), Celebrating scholarly communication studies: A Festschrift for Olle Persson at his 60th Birthday (pp. 9-24). Leuven: International Society for Scientometrics and Informetrics.

Putnam, R. D. (2001). Bowling alone: the collapse and revival of American community. New York: Simon and Schuster.

Ramos-Rincón, J. M., Pinargote-Celorio, H., Belinchón-Romero, I., \& González-Alcaide, G. (2019). A snapshot of pneumonia research activity and collaboration patterns (2001-2015): A global bibliometric analysis. BMC Medical Research Methodology, 19, 184. https://doi.org/10.1186/s12874-019-0819-4.

Ravasi, D., \& Schultz, M. (2006). Responding to organizational identity threats: Exploring the role of organizational culture. Academy of Management Journal, 49(3), 433-458. https://doi.org/10.2307/20159 775 .

Reagans, R., \& McEvily, B. (2003). Network structure and knowledge transfer: The effects of cohesion and range. Administrative Science Quarterly, 48(2), 240-267. https://doi.org/10.2307/3556658.

Rumsey-Wairepo, A. (2006). The association between co-authorship network structures and successful academic publishing among higher education scholars. Provo, Utah: Brigham Young University.

Scott, J. (1991). Social network analysis: A handbook. London: Sage.

Song, Z., Wang, S., \& Lee, D. (2018). Periphery authors, network embeddedness, and research impact: The case of Chinese inland scholars. The International Journal of Business Management and Technology, 2(2), 17-22.

Tushman, M. L. (1977). Special boundary roles in the innovation process. Administrative Science Quarterly, 22(4), 587-605.

Uddin, S., Hossain, L., Abbasi, A., \& Rasmussen, K. (2012). Trend and efficiency analysis of co-authorship network. Scientometrics, 90(2), 687-699. https://doi.org/10.1007/s11192-011-0511-x.

Valente, T. W., Coronges, K., Lakon, C., \& Costenbader, E. (2008). How correlated are network centrality measures? Connect (Tor), 28(1), 16-26.

Valente, T., \& Fujimoto, K. (2010). Bridging: Locating critical connectors in a network. Social Networks, 32(3), 212-220. https://doi.org/10.1016/j.socnet.2010.03.003.

Vanni, T., Mesa-Frias, M., Sanchez-Garcia, R., Roesler, R., Schwartsmann, G., Goldani, M. Z., et al. (2014). International scientific collaboration in HIV and HPV: A network analysis Plos One, 9(3), e93376. https://doi.org/10.1371/journal.pone.0093376.

Vedres, B., \& Stark, D. (2010). Structural folds: Generative disruption in overlapping groups. American Journal of Sociology, 115(4), 1150-1190. https://doi.org/10.1086/649497.

Wagner, C. S., Horlings, E., Whetsell, T. A., Mattsson, P., \& Nordqvist, K. (2015). Do nobel laureates create prize-winning networks? An analysis of collaborative research in Physiology of Medicine. PLoS ONE, 10(7), e0134164. https://doi.org/10.1371/journal.pone.0134164.

Watts, D. J., \& Strogatz, S. H. (1998). Collective dynamics of "small-world" networks. Nature, 393(6684), 409-410. https://doi.org/10.1038/30918.

Wasko, M. M., \& Faraj, S. (2005). Why should I share? Examining social capital and knowledge contribution in electronic networks of practice. MIS Quarterly, 29(1), 35-57. https://doi.org/10.2307/25148 667.

Woolcock, M., \& Deepa, N. (2000). Social capital: Implications for development theory, research and policy. The World Bank Research Observer, 15(2), 225-249.

Yan, E., \& Ding, Y. (2009). Applying centrality measures to impact analysis: A coauthorship network analysis. Journal of the American Society for Information Science and Technology, 60(10), 2107-2118. https://doi.org/10.1002/asi.21128.

Yu, Q., Shao, H., He, P., \& Duan, Z. (2013). World scientific collaboration in coronary heart disease research. International Journal of Cardiology, 167(3), 631-639. https://doi.org/10.1016/j.ijcar d.2012.09.134. 